\title{
New Options in the Treatment of Lipid Disorders in HIV-Infected Patients
}

\author{
Erika Ferrari Rafael da Silva ${ }^{*}, 1$ and Giuseppe Bárbaro ${ }^{2}$ \\ ${ }^{I}$ Federal University of São Paulo, R Loefgren, 1588, Zip Code04040 002, São Paulo, Brazil \\ ${ }^{2}$ Cardiology Unit, Department of Medical Pathophysiology, University La sapienza, Rome, Italy
}

\begin{abstract}
Since the introduction of HAART, there was a remarkably change in the natural history of HIV disease, leading to a notable extension of life expectancy, although prolonged metabolic imbalances could significantly act on the longterm prognosis and outcome of HIV-infected persons, and there is an increasing concern about the cardiovascular risk in this population. Current recommendations suggest that HIV-infected perons undergo evaluation and treatment on the basis of the Third National Cholesterol Education Program Expert Panel on Detection, Evaluation and Treatment of High Blood Cholesterol in Adults (NCEP ATP III) guidelines for dyslipidemia, with particular attention to potential drug interactions with antiretroviral agents and maintenance of virologic control of HIV infection. While a hypolipidemic diet and physical activity may certainly improve dyslipidemia, pharmacological treatment becomes indispensable when serum lipid are excessively high for a long time or the patient has a high cardiovascular risk, since the suspension or change of an effective antiretroviral therapy is not recommended. Moreover, the choice of a hypolipidemic drug is often a reason of concern, since expected drug-drug interactions (especially with antiretroviral agents), toxicity, intolerance, effects on concurrent HIV-related disease and decrease patient adherence to multiple pharmacological regimens must be carefully evaluated. Often the lipid goals of patients in this group are not achieved by the therapy recommended in the current lipid guidelines and in this article we describe other possibilities to treat lipid disorders in HIV-infected persons, like rosuvastatin, ezetimibe and fish oil.
\end{abstract}

Keywords: Human immunodefciency virus, acquired immunodeficiency syndrome, highly active antiretroviral therapy, dyslipidemia, statins, fish oil, ezetimibe.

\section{INTRODUCTION}

Disorders of lipid metabolism have been described in patients with HIV infection before the introduction of highly active antiretroviral therapy (HAART), including increased serum triglyceride (TG) levels and decreased cholesterol levels observed in advanced stages of HIV infection [1-3]. However, laboratory and clinical abnormalities of lipid metabolism have also been increasingly recognized after the advent of HAART. Significant increases in plasma TG and total cholesterol (TC) concentrations, often associated with abnormal body fat distribution and glucose metabolism alterations (such as peripheral insulin resistance, hyperinsulinemia, hyperglycemia and diabetes mellitus), have been reported specially in protease inhibitors (PI)treated patients [4-6]. For details see Table 1. Since the introduction of HAART, there was a remarkably change in the natural history of HIV disease, leading to a notable extension of life expectancy, although prolonged metabolic imbalances could significantly act on the long-term prognosis and outcome of HIV-infected persons, and there is an increasing concern about the cardiovascular risk in this population $[4,7,8]$. While a hypolipidemic diet and physical activity may certainly improve dyslipidemia, pharmacological treatment becomes indispensable when

*Address correspondence to this author at the Federal University of São Paulo, R Loefgren, 1588, Zip Code04040 002, São Paulo, Brazil; Tel: 5511 5081 8972; Fax: 55115081 8972;

E-mails: erikaferrari@uol.com.br, ferrarierika76@hotmail.com serum lipid are excessively high for a long time or the patient has a high cardiovascular risk, since the suspension or change of an effective antiretroviral therapy is not recommended [9]. Moreover, the choice of a hypolipidemic drug is often a reason of concern, since expected drug-drug interactions (especially with antiretroviral agents), toxicity, intolerance, effects on concurrent HIV-related disease and decrease patient adherence to multiple pharmacological regimens must be carefully evaluated $[8,10]$. HIV infected person have an increase risk of coronary artery disease (CAD) [11]. Part of this risk may be due to the hyperlipidemia associated with antiretroviral treatment $[11,12]$. Often the lipid goals of patients in this group are not achieved by the therapy recommended in the current lipid guidelines [3] and in this article we describe others possibilities to treat lipid disorders in HIV-infected persons.

\section{PATHOGENESIS FOR DYSLIPIDEMIA}

\section{PIs- Associated Metabolic Alterations}

PIs target the catalytic region of HIV-1 protease. This region is homologous with regions of two human proteins that regulate lipid metabolism: cytoplasmic retinoic-acid binding protein-1 (CRABP-1) and low density lipoproteinreceptor-related protein (LRP) $[13,14]$. It is hypothesized that PIs inhibit CRABP-1-modified and cytrochrome P450 3- mediated synthesis of cis-9 retinoic acid and peroxisome proliferator activated receptor (PPAR $\partial$ ) heterodimer. The inhibition increases the rate of apoptosis of adipocytes and reduces the rate at which pre-adipocytes differentiate into 
adipocytes, with the final effect of reducing TG storage and increasing lipid release. PIs-binding to LRP would impair hepatic chylomicron uptake and endothelial TG clearance, resulting in hyperlipidemia and insulin resistance $[13,14]$.

Table 1. Changes in Lipid Metabolism in HIV Infection

\begin{tabular}{|ll|}
\hline HIV-Infected Naïve Patients & \\
\hline$\uparrow$ Triglyceride & \\
$\uparrow$ VLDL & \\
$\uparrow$ VLDL triglyceride production rates & \\
$\uparrow$ Small, dense LDL & \\
\hline HIV Patients Treated with IP Based Regimen \\
$\uparrow$ Triglyceride & \\
$\uparrow$ Total Cholesterol & \\
$\uparrow$ VLDL, IDL, LDL-c, cholesterol & $\downarrow$ Postprandial delipidation \\
$\uparrow$ Apo B-100 & $\downarrow$ VLDL to IDL/LDL transfer \\
$\uparrow$ Apo E & $\downarrow$ VLDL and LDL catabolic rates \\
$\uparrow$ ApoC-III & $\downarrow$ Hepatic lipase activity \\
$\uparrow$ VLDL production & $\downarrow$ Lipoprotein lipase activity \\
\hline & VLDL - very low-density lipoprotein (LDL), HDL - high density lipoprotein, IDL - \\
intermediate-density lipoprotein, Apo - apolipoprotein.
\end{tabular}

Some data indicate that PI-associated dyslipidemia may be caused, at least in part, by PI-mediated inhibition of proteasome activity and accumulation of the active portion of sterol regulatory element-binding protein (SREBP)-1c in liver cells and adipocytes or by apoliprotein (apo) CIII polymorphisms in HIV-infected persons [15]. The observed excess of apo CIII in lipoprotein might be a major determinant of a slower catabolism of triglyceride-rich lipoproteins because apo CIII is an inhibitor of lipoprotein lipase activity and also impairs the interaction of apo B and apo E with LDL receptor and LRP. This will result in an increased level of remnant lipoprotein returning to the liver $[15,16]$. Sequence homologies have been described between HIV-1 protease and human site-1 protease (S1P), which activates SREBP-1c and SREBP-2 pathways. A polymorphism in the S1P/SREBP-1c genes confers a difference in risk for development of an increase in TC with PI therapy, suggesting a possible genetic predisposition to hyperlipoproteinemia in PI-treated patients [17]. Caron et al. [17] reported that some PIs may impair the nuclear location of SREBP-1 and alter the structure and stability of the nuclear lamina possibly by impairing the maturation of prelamin A to lamin A. Lamin A and lamin C are encoded by the same gene and can combine with lamin B to form a network of filamentous proteins located at the inner face of the nuclear membrane called lamina [17]. Lamina interacts with the nuclear membrane and with chromatin. In particular, the C-terminal globular domain of lamin $\mathrm{A} / \mathrm{C}$ can bind DNA and also SERBP-1 [17]. Cells from these patients have nuclear alterations and altered lamina stability, similar to the alterations induced in cultured adipocytes by some PIs [17]. It is possible to hypothesize that some PIs may alter the lamina structure and thereby alter the normal location of SREBP-1 inside the nucleus [17]. This could impair adipocyte differentiation and induce insulin resistance. Moreover, some PIs may alter the expression of adipocytokines in cultured adipocytes [18], increasing the expression of proinflammatory cytokines TNF- $\alpha$ and IL-6, which are known to play a pathogenetic role in adipose tissue apoptosis and decreasing the expression of adiponectin, which is associated with the development of insulin resistance [18].

\section{Treatment Considerations}

The studies published until now show that dyslipidemia in HIV-infected persons carries the same degree of cardiovascular risk as in HIV-negative population [19]. Nowadays the benefits of lipid-lowering interventions have been extended to HIV-infected persons. Further, there is currently no basis for a more aggressive intervention among HIV-infected persons than what is currently recommended for the general population. Because there is a significant possibility for drug interaction of some lipid-lowering agents with antiretroviral drugs (in particular statins are metabolized through the cytochrome (CYP) P450 system), care should be given to the choice of lipid-lowering agents. Current recommendations suggest that HIV-infected persons undergo evaluation and treatment on the basis of the Third National Cholesterol Education Program Expert Panel on Detection, Evaluation and Treatment of High Blood Cholesterol in Adults (NCEP ATP III) guidelines for dyslipidemia, with particular attention to potential drug interactions with antiretroviral agents and maintenance of virologic control of HIV infection. Nonpharmacologic measures remain the basis for intervention. The initial choice for hypertriglyceridemia is fibrate, and for elevated LDL-c, statins [20].

According to the US-based Adult AIDS Clinical Trial Group (AACTG) Cardiovascular Disease Focus Group, treatment with pravastatin, fluvastatin or atorvastatin is recommended for antiretroviral-linked hypercholesterolemia, while lovastatin and simvastatin should be avoided due to interactions with PIs or non-nucleoside reverse transcriptase inhibitors (NNRTI) [21] and the risk of skeletal muscle toxicity. Many studies that evaluate the effect of statins for the treatment of antiretroviral-associated dyslipidemia have shown only partial responses to such therapy, with total and LDL-c values being reduced by just 25\% [22].

Statins are considered the current first-line therapy for primary hypercholesterolemia and showed beneficial effects in both reducing total and LDL-c cholesterol levels in the HIV-negative persons [23]. Because of the variable metabolism through CYP 3A4, significant interactions have been documented with potent CYP 3A4 inhibitors (such as itraconazole, cyclosporine, oral anticoagulants, PIs and delaverdine), which cause elevated levels of statins, leading to a significantly increase of liver and skeletal muscle toxicity [23]. Lovastatin and simvasatin are administered as inactive lactone prodrugs that are avidly metabolized by intestinal and hepatic CYP 3A4. On the other hand, pravastatin, atorvastatin and fluvastatin are administered directly as the active hydroxyl-acid. Pravastatin is eliminated mostly by glucoronidation, fluvastatin by CYP $2 \mathrm{C} 9$ isoform, and CYP 3A4 has no role in their metabolism [24]. On the basis on the clinical and experimental data, simvastin and lovastatin should not be used in patients taking PIs or 
Table 2. Lipid Lowering Therapy for HIV-Infected People

\begin{tabular}{|c|c|c|}
\hline $\begin{array}{l}\text { Elevated LDL-c or } \\
\text { non-HDL } \\
\text { cholesterol with } \\
\text { triglycerides level of } \\
200-500 \mathrm{mg} / \mathrm{dL}\end{array}$ & $\begin{aligned} \text { Statins: } & \\
\text { - } & \text { Pravastatin: } 20-40 \mathrm{mg} \text { daily } \\
\text { - } & \text { Atorvastatin: } 10-20 \mathrm{mg} / \text { daily } \\
\text { - } & \text { Fluvastatin: } 20-40 \mathrm{mg} \text { daily } \\
\text { - } & \text { Rosuvastatin } \\
\text { - } & \text { Lovastatin } \\
\text { - } & \text { Simvastatin } \\
\text { - } & \text { Ezetimibe: } 10 \mathrm{mg} \text { daily }\end{aligned}$ & $\begin{array}{l}\text { Less drug interaction potential } \\
\text { Used with caution in lower doses when combined with PIs and NNRTIs } \\
\text { Minimal drug interaction potential. Not widely used due to low potency } \\
\text { Most potent statin. May be used safely with antiretroviral } \\
\text { Avoid in patients taking PIs } \\
\text { Avoid in patients taking PIs or delaverdine } \\
\text { Can be used with statin or in monotherapy }\end{array}$ \\
\hline $\begin{array}{l}\text { triglycerides level > } \\
500 \mathrm{mg} / \mathrm{dL}\end{array}$ & 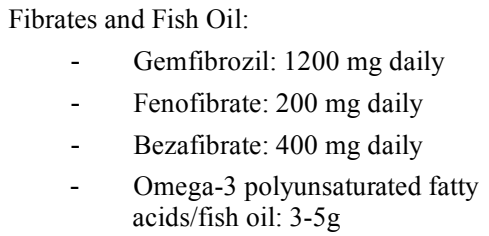 & $\begin{array}{l}\text { Caution when used with statins in mixed dyslipidemia } \\
\text { Caution when used with statins in mixed dyslipidemia } \\
\text { First line therapy for hypertriglyceridemia } \\
\text { Evidence suggest fish oil may decrease triglycerides and increase HDL-c, } \\
\text { however can also increase LDL-c }\end{array}$ \\
\hline
\end{tabular}

NNRTIs, atorvastatin can be used with caution (at low initial doses) and pravastatin and fluvastatin appear to be safe for use in association with HAART [19]. Table $\mathbf{2}$ has a summary of the lipid lowering therapy in HIV infected persons.

\section{Rosuvastatin}

Rosuvastatin is a 3-hydroxy-3-methylglutaryl coenzyme A (HMG-CoA) inhibitor that showed the highest dose-todose potency in lowering total and LDL-c levels, compared with other currently available statins. It works also to reduce TG and increase HDL-c. Moreover, pharmacokinetic studies have demonstrated that its metabolism is not dependent on the CYP 450 3A4 isoenzyme and its use could be considered in PI-treated individuals as the result of the low risk of drugdrug interactions [25]. Only $10 \%$ of the administered dose is metabolized by CYP 2C9 isoenzyme into N-desmethyl rosuvastatin and its metabolite are $90 \%$ eliminated by the fecal route [24-26]. The usual recommended starting dose of rosuvastatin is $10 \mathrm{mg}$ daily, but initiation at $5 \mathrm{mg}$ daily may be considered for patients who have predisposing factors for myopathy or are taking cysclosporine. In subjects with severe renal impairment or taking fibrates, therapy with rosuvastatin should only be used with great caution, daily dose should be initiated at $5 \mathrm{mg}$ and not exceed $10 \mathrm{mg}$ [26].

In the research of Bottero et al. [27], the use of rosuvastatin (10 $\mathrm{mg} /$ day) was retrospective evaluated during 16 weeks in HAART-treated HIV-infected persons with dyslipidemia. Seventy eight patients started on rosuvastatin, sixty as monotherapy. After 16 weeks of treatment, a significant decrease was seen in both LDL-c and non-HDL (31,3\% and $29,9 \%$ reduction respectively). The decrease in triglyceride was also significant $(34,1 \%)$. Rosuvastatin was safe and effective in the treatment of dyslipidemia in HAART-treated HIV-infected persons. The results showed above are similar to the HIV-uninfected population. Calza et al. [28] in an open label, randomized, prospective study evaluated the role of rosuvastatin (10 $\mathrm{mg}$ once daily), pravastatin (20 mg once daily) and atorvastatin (10 mg once daily) in the treatment of hypercholesterolemia (TC $>250$ $\mathrm{mg} / \mathrm{dL}$ ) in HIV-infected persons at least 3 month duration and unresponsive to a hypolipidemic diet and physical exercise. Eighty five subjects completed the study and the mean reduction after one year follow up was $21,2 \%$ and $23,6 \%$ versus baseline TC and LDL-c levels, respectively $(\mathrm{p}=0.002)$. Mean decrease in TC concentration was significantly greater with rosuvastatin $(25,2 \%)$ than with pravastatin $(17,6 \% \mathrm{p}=0.01)$ and atorvastatin $(19,8 \% \mathrm{p}=$ $0.03)$. All the statins showed a favourable tolerability profile, but rosuvastatin was found to be more effective. Van der Lee et al. [29] evaluated the pharmacokinectics and pharmacodynamics of combined use of lopinavir/ritonavir and rosuvastatin $(10 \mathrm{mg}, 20 \mathrm{mg}$ and $40 \mathrm{mg}$ ) in $\mathrm{HV}$-infected persons and found that the levels of this PI were not affected by the administration of rosuvastatin, but the rosuvastin levels unexpectedly appeared to be 1.6 fold compared with healthy volunteers. Larger studies are necessary to confirm these findings, until there, the combination of rosuvastin and lopinavir/ritonavir should be used with caution.

\section{Ezetimibe}

Ezetimibe is the first lipid-lowering drug that inhibits intestinal uptake of dietary and biliary cholesterol at the brush border of the intestine, resulting in a reduction of hepatic cholesterol stores and an increase in clearance of cholesterol form in the blood [30]. It doesn't affect the absorption of fat-soluble nutrients and is an attractive option for HIV-infected persons because it lacks CYP P450 metabolism and therefore is not expected to interact with antiretroviral [30,31]. It reduces cholesterol absorption in the duodenum by approximately 50\%, thereby attaining reductions in LDL-c of $20 \%$ [32]. This benefit is significantly greater when it is given with any of the statins, achieving reductions in LDL-c of up to $50 \%$ [32,33]. This synergistic effect of the two drugs in combination results from the inhibition of duodenal cholesterol absorption by ezetimibe, together with the reduction of hepatic cholesterol production by the statins [30]. Following oral administration, 
ezetimibe is rapidly absorbed and extensively metabolized $(>80 \%)$ to the pharmacologically active ezetimibeglucuronide [30]. The recommended dose is $10 \mathrm{mg} / \mathrm{day}$, and can be administered in the morning or evening without regard to food [30]. The major metabolic pathway for Ezetimibe consists of glucuronidation of 4-hydroxyphenyl group by uridine 5 '-diphosphate-glucuronosyltransferase isoenzymes to form ezetimibe-glucuronide in the intestine and liver [30]. It has a favourable drug-drug interaction profile. Ezetimibe does not have significant effects on plasma levels of HMG-CoA reductase inhibitors known as statins (atorvastatin, fluvastatin, lovastatin, pitavastatin, pravastatin, rosuvastatin, simvastatin), fibric acid derivatives (gemfibrozil, fenofibrate), digoxin, glipizide, warfarin and triphasic oral contraceptives (ethinylestradiol and levonorgestrel). Concomitant administration of food, antiacids, cimetidine or statins had no significant effect on ezetimibe bioavailability [34].

Ezetimibe has been effective in optimizing lipid levels when added to traditional therapy in non-HIV infected persons [34-36]. In HIV positive population some studies have assessed the efficacy of this drug and are described as follow. Coll et al. [37] showed that ezetimibe monotherapy decreases LDL-c as effectively as fluvastatin monotherapy. Twenty HIV-infected persons were randomly assigned to receive ezetimibe $(10 \mathrm{mg} /$ day $)$ or fluvastatin $(80 \mathrm{mg} /$ day $)$. Patients receiving ezetimibe experienced a statistically significant $(\mathrm{p}=0,003) 20 \%$ reduction in the concentration of LDL-c, similar to that observed with fluvastatin $(24 \%, p$ between groups 0.70). Negredo et al. [30] conducted a prospective study and Ezetimibe was added when the statin (pravastatin monotherapy) has poor response. During 24 weeks, nineteen patients received ezetimibe $(10 \mathrm{mg} /$ day $)$ and pravastatin $(20 \mathrm{mg} /$ day $)$, while the patients maintained the same antiretroviral regimen. At week $24,61,5 \%$ of patients achieved the endpoint of the study (LDL-c $<130 \mathrm{mg} / \mathrm{dL}$ ). Significant declines in total and LDL-c levels were observed between baseline and weeks $6,12,24$, irrespective of antiretroviral regimen (IP or ITRNN) and mean HDL-c increased significantly. No patients discontinued therapy due to intolerance or toxicity. The addition of ezetimibe to ongoing pravastin was effective and a safe option for HIVinfected persons not achieving the NCEP ATP III LDL-c goals despite receiving a statin alone. Bennet et al. [38], added ezetimibe to maximally tolerated lipid lowering therapy (statins or fenofibrate) in 33 HIV infected persons. The mean TC and LDL-c were reduced $21 \%$ and $35 \%$ respectively $(\mathrm{p}<0.001)$ and HDL-c increased $8 \%(\mathrm{p}=0.038)$. No adverse events occurred. Stebbin et al. [39] analyzed twenty nine HIV-infected persons with ezetimibe alone or associated with statins. Of these individuals, 16 and 11 respectively were receiving PI-based and NNRTI-based regimen. During 12 weeks, it was observed a significant reduction of $18 \%$ in TC $(p<0.01)$ and $28,9 \%$ in TG $(\mathrm{p}<0.05)$ regardless of whether patients received statins or not, or the type of antiretroviral therapy. In the end of study, $40 \%$ of the patients had normalized serum TC, but the same didn't occur with TG. There were no significant differences in reduction of either serum $\mathrm{TC}$ or $\mathrm{TG}$ in those receiving ezetimibe alone $(n=12)$ or combined with statins $(n=17)$. The limitations of this study included small sample size and lack of measurement of LDL-c level. Van den Berg-Wolf et al. [40] in a prospective, non controlled study, evaluated twenty HIV-infected persons who were on treatment with statins and didn't reach the LDL-c goal during 18 weeks. These patients were on HAART that included ritonavir-boosted PIs in $17(85 \%)$ and $3(15 \%)$ on nelfinavir. Mean percentage of changes from baseline in LDL-c were: $-10,9 \%,-12,2 \%$ and $-9,1 \%$ at weeks $6,12,18$, respectively ( $<<0.05$ at each time period $v s$ baseline). No significant changes in TG and HDL-c were seen. In a subgroup of patients on lopinavir/ritonavir $(\mathrm{LPV} / \mathrm{r})$, the concentrations of the drug were obtained before and after the introduction of Ezetimibe and no significant changes were observed in the concentration of this PI.

Ezetimibe could be recommended as a second line therapy to HAART induced dyslipidemia if hypercholesterolemia is refractory to the statins or if the patient does not tolerate these drugs. Its high tolerability and the lack of interactions with the CYP 3A4 indicate that ezetimibe will not increase the risk of toxicity or pharmacokinetic interactions with antiretroviral.

\section{Fish Oil}

The metabolic effects of N-polyunsaturated fatty acids (PUFAs) derived from marine sources (so-called "fish oils") have been demonstrated to reduce fasting and postprandial TG levels in subjects without HIV infection [41]. Omega-3 is considered an alternative treatment in non-HIV infected persons. Interest in the triglyceride-lowering effect of omega-3 fatty acids first came from studies in Greenlandic Eskimos, which showed that, despite high intake of animal fats, there was low incidence of CAD. A contributing factor was the type of fats being consumed, which were rich in omega-3 fatty acids $[42,43]$ however the exact mechanism whereby these fats decrease the risk of CAD is unclear. It has been demonstrated that 3-5 g per day of omega-3 fatty acids can reduce triglycerides by $30-50 \%$, thereby potentially minimizing the risk of coronary heart disease (CHD) and pancreatitis [44]. Intake of small amounts of fish has also been shown to affect mortality [44]. One research showed that, in addition to significantly lowering plasma levels of TC, LDL-c and VLDL-c, salmon oil and other omega-3enriched fish oils can have a potentially therapeutic role in the treatment of very high plasma TG levels [45-48]. Few data are available on the effect of PUFAs on metabolic abnormalities in HIV persons [49] however recent studies suggest possible efficacy and safety of fish oil supplementation in the treatment of antiretroviral therapyassociated hypertriglyceridemia [50].

Whol et al. [50] conducted an open-label, randomized trial with 52 patients receiving HAART with fasting TG levels of $>200 \mathrm{mg} / \mathrm{dL}$ to receive nutritionist-administered dietary and exercise counseling with or without fish oil supplementation for 16 weeks. Patients assigned to receive fish oil had a $25 \%$ decline in fasting TG levels at week 4 ( $95 \% \mathrm{CI},-34.6 \%$ to $-15.7 \%$ change), compared with a $2.8 \%$ mean increase among patients assigned to receive counseling alone $(95 \% \mathrm{CI},-17.5 \%$ to $+23.1 \%$ change $\mathrm{p}=.007)$. By 
week 16, the mean reduction in TG levels in the fish oil arm remained significant at $19.5 \%(95 \% \mathrm{CI},-34.9 \%$ to $-4.0 \%$ change), whereas the mean decrease in the diet and exercise only arm was $5.7 \%$ (95\% CI $-24.6 \%$ to $+13.2 \%$ change); however, the difference between study arms was no longer statistically significant $(\mathrm{p}=.12)$. Low density lipoprotein cholesterol levels had increased by $15.6 \%$ (95\% CI, $+4.8 \%$ to $+26.4 \%$ change), at week 4 and by $22.4 \%$ (95\% CI, + $7.91 \%$ to $+36.8 \%$ change) at week 16 in the fish oil arm but did not change in the other group. Carter et al. [51] compared the effectiveness of omega-3 fatty acid supplementations and placebo in lowering TG levels in HIVinfected persons on HAART. It was a placebo-controlled, randomized, double-blind trial in participants with stable HAART with fasting TG $>312 \mathrm{mg} / \mathrm{dL}^{*}$ to $890 \mathrm{mg} / \mathrm{dL}^{*}$ using $9 \mathrm{~g}$ of omega-3 fatty acids versus placebo (olive oil) after 6 week lead in on dietary therapy. Eleven HIV-infected males were enrolled. The mean TG level decreased from 447 $\mathrm{mg} / \mathrm{dL}^{*}$ at baseline to $395 \mathrm{mg} / \mathrm{dL}^{*}(-11.6 \%)$ after dietary intervention and to $300 \mathrm{mg} / \mathrm{dL}^{*}(-32.9 \%)$ after 8-week treatment period. In the omega-3 fatty acid arm, TG fell from $475 \mathrm{mg} / \mathrm{dL}$ to $447 \mathrm{mg} / \mathrm{dL}^{*}(-6 \%)$ after dietary intervention and to $210 \mathrm{mg} / \mathrm{dL}^{*}(-56.9 \%)$ after treatment period. In the placebo arm, TG fell from $425 \mathrm{mg} / \mathrm{dL}$ to $361 \mathrm{mg} / \mathrm{dL}^{*}$ (- $15.1 \%)$ after dietary intervention and to $363 \mathrm{mg} / \mathrm{dL}^{*}$ $(-14.5 \%)$ after the treatment period. The difference between the groups was significant $(\mathrm{p}=0.0487)$. The estimated difference between groups for change in mean TG over 8weeks was - $207 \mathrm{mg} / \mathrm{dL}^{*}$ (CI $95 \%$ - 402 to $-11 \mathrm{mg} / \mathrm{dL}$ ). De Truchis et al. [52] evaluated the TG levels in HIV-infected persons receiving stable antiretroviral therapy treated with PUFAs in a prospective double-blind randomized design. One hundred twenty two patients with TG $>200 \mathrm{mg} / \mathrm{dL}^{*}$ and $\leq 1000 \mathrm{mg} / \mathrm{dL}^{*}$ after 4 -week diet were randomized for 8 weeks to N-3 PUFAs (2 capsules containing $1 \mathrm{~g}$ of fish oil 3 times daily, $\mathrm{n}=60$ ) or placebo ( $1 \mathrm{~g}$ of paraffin oil capsules, $\mathrm{n}=62$ ). An 8-week open-label phase of N-3 PUFAs followed. The difference (PUFA versus placebo) in TG percent change at week 8 was $-24.6 \%$ (range: $-40.9 \%$ to $-8.4 \%$; $\mathrm{p}=$ 0.0033 ), the median was $-25.5 \%$ in the PUFA group versus $1 \%$ in placebo group and mean TG levels at week 8 were $340 \pm 180 \mathrm{mg} / \mathrm{dL}^{*}$ and $480 \pm 310 \mathrm{mg} / \mathrm{dL}^{*}$ respectively. The TG levels were normalized in $22.4 \%$ (PUFA) versus $6.5 \%$ (placebo) $(\mathrm{p}=0.013)$ with $\mathrm{a} \geq 20 \%$ reduction in $58.6 \%$ (PUFA) versus $33.9 \%$ (placebo) ( $\mathrm{p}=0.007)$. Under the openlabel phase of N-3 PUFAs, the decrease in TG levels was sustained at week 16 for patients in the PUFA group (mean TG levels: $340 \pm 170 \mathrm{mg} / \mathrm{dL}^{*}$, whereas a $21.2 \%$ decrease in TG levels occurred in the placebo group (mean TG levels: $330 \pm 140 \mathrm{mg} / \mathrm{dL}^{*}$. The median TG change at week 8 was $43.6 \%$ (range Q1-Q3; 95\% CI: - $66.5 \%$ to - 4.6\%) for patients with TG levels $>1000 \mathrm{mg} / \mathrm{dL}$. Manfredi et al. [49] in a prospective, open-label study, evaluated the efficacy and safety profile of polyunsaturated ethyl esters of n-3 fatty acids (PEEs) in the control of moderate hypertriglyceridemia complicating antiretroviral-treated HIV disease, compared with diet and exercise and with fibrate. Patients with moderate hypertriglyceridemia $(200-500 \mathrm{mg} / \mathrm{dL})$ while on HAART, despite modified diet and increased physical activity were selected. A total of 156 patients aged 36-62 years (97 men) were evaluated. Fifty four patients received PEE at $1 \mathrm{~g}$ twice daily; 53 subjects were treated with standard doses of either: bezafibrate ( 21 cases), fenofibrate (19 cases) or gemfibrozil (13 cases); and the remaining 49 patients continued a diet-exercise program and served as controls. An analysis of 18 months showed that continued PEE administration led to a significant decrease of mean TG of $5.6 ; 15.8,13.3,16 ; 15.3$ and $11.6 \%$ after $3,6,9,12,15$ and 18 months, respectively $(\mathrm{P}<0.0001$ vs baseline levels), while negligible changes occurred in serum cholesterolemia. Both PEE and fibrate administration achieved a significant $(\mathrm{p}<$ 0.0001 ) amelioration of triglyceridemia compared with dietexercise only, although fibrates showed a better efficacy profile $v s$ PEE $(\mathrm{p}<0.0001)$; these significance levels were maintained throughout the entire 18-month observation period. When comparing the efficacy of PEE with that of a diet-exercise program, a significant difference was reached at the $6^{\text {th }}$ month $(\mathrm{p}=0.001)$ and was maintained until the $18^{\text {th }}$ month ( $p=0.005-\mathrm{P}<0.0001)$. It showed that pharmaceutical interventions for extreme hyperlipidaemia will continue to be superior to dietary therapy alone and that omega-3 fatty acid will be a useful additional intervention in HIV-infected people with hypertriglyceridemia.

\section{CONCLUSION}

All HIV-infected persons should have their fasting plasma lipid profile prior to starting HAART. These exams should be repeated 2 to 3 months after starting or changing antiretroviral therapy, every 2 to 3 months with the existing of significant abnormalities and to assess response to lipidlowering therapy. It should be checked annually in the absence of significant abnormalities or well-achieved targets as a result of intervention. Efforts should be used including lifestyle modification and lipid-lowering agents if it is necessary, to achieve lipids goals. Special attention should be given to drug interactions between lipid-lowering agents and antiretroviral therapy. Neither, lovastatin or simvastatin should be used with PI and atorvastatin should be used with caution. Rosuvastatin is a new statin with promising results in HIV-infected people. Ezetimibe is the first lipid-lowering drug that inhibits intestinal uptake of dietary and biliary cholesterol at the brush border of the intestine and researches showed that it could be used as monotherapy or combined with statin. Omega-3 is considered an alternative treatment in non-HIV infected populations and that this fish oil could be used to treat high TG levels related to HAART.

\section{REFERENCES}

[1] Constans J, Pellegrin JL, Peuchant E, et al. Plasma lipids in HIVinfected patients: a prospective study in 95 patients. Eur J Clin Invest 1994; 24(6): 416-20.

[2] Grunfeld C, Kotler DP, Shigenaga JK, et al. Circulating interferonalpha levels and hypertriglyceridemia in the acquired immunodeficiency syndrome. Am J Med 1991; 90(2): 154-62.

[3] Shor-Posner G, Basit A, Lu Y, et al. Hypocholesterolaemia is associated with immune dysfunction in early human immunodeficiency virus-1 infection. Am J Med 1993; 94(5): 515-9.

[4] Graham NM. Metabolic disorders among HIV-infected patients treated with protease inhibitors: a review. J Acquir Immune Defic Syndr 2000; 25 (Suppl 1): S4-11.

[5] Distler O, Cooper DA, Deckelbaum RJ, Sturley SL. Hyperlipidemia and inhibitors of HIV protease. Curr Opin Clin Nutr Metab Care 2001; 4(2): 99-103. 
[6] Barbaro G. Reviewing the cardiovascular complications of HIV infection after the introduction of highly active antiretroviral therapy. Curr Drug Targets Cardiovasc Haematol Disord 2005; 5(4): 337-43.

[7] Palella FJ, Delaney KM, Moorman AC, et al. Declining morbidity and mortality among patients with advanced human immunodeficiency virus infection. N Engl J Med 1998; 338: 85360.

[8] Manfredi R. Management of dyslipidemia in patients with HIV disease. Clin Microbiol Infect 2000; 6(11): 579-84.

[9] Carpenter CC, Cooper DA, Fischl MA, et al. Antiretroviral therapy in adults: updated recommendations of the International AIDS Society-USA Panel. JAMA 2000; 283(3): 381-90.

[10] Currier JS. How to manage metabolic complications of HIV therapy: what to do while we wait for answers. AIDS Read 2000; 10 (3): $162-9$.

[11] Klein D, Hurley LB, Quesenberry CP, Jr, Sidney S. Do protease inhibitors increase the risk for coronary heart disease in patients with HIV-1 infection? J Acquir Immune Defic Syndr 2002; 30(5): 471-7.

[12] Mary-Krause M, Cotte L, Simon A, Partisani M, Costagliola D. Clinical Epidemiology Group from the French Hospital Database. Increased risk for myocardial infarction with duration of protease inhibitor therapy in HIV-infected men. AIDS 2003; 17: 2479-86.

[13] Carr A, Samaras K, Burton S, et al. A syndrome of peripheral lipodystrophy, hyperlipidaemia and insulin resistance in patients receiving HIV protease inhibitors. AIDS 1998; 12: F51-F58.

[14] Carr A, Samaras K, Chisholm DJ, Cooper DA. Pathogenesis of HIV-1-protease inhibitor-associated peripheral lipodystrophy, hyperlipidaemia, and insulin resistance. Lancet 1998; 351 (9119): 1881-3.

[15] Fauvel J, Bonnet E, Ruidavets JB, et al. An interaction between apo C-III variants and protease inhibitors contributes to high triglyceride/low HDL levels in treated HIV patients. AIDS 2001; 15 (18): 2397-406.

[16] Bonnet E, Ruidavets JB, Tuech J, et al. Apoprotein c-III and Econtaining lipoparticles are markedly increased in HIV-infected patients treated with protease inhibitors: association with the development of lipodystrophy. J Clin Endocrinol Metab 2001; 86 (1): 296-302.

[17] Caron M, Auclair M, Sterlingot H, Kornprobst M, Capeau J. Some HIV protease inhibitors alter lamin $\mathrm{A} / \mathrm{C}$ maturation and stability, SREBP-1 nuclear localization and adipocyte differentiation. AIDS 2003; 17(17): 2437-44.

[18] Jones SP, Janneh O, Back DJ, Primohammed M. Altered adipocytokines gene expression in murine 3T3-F442A adipocyte treated with protease inhibitors and nucleoside reverse transcriptase inhibitors. Antivir Ther 2003; 8: 1-11.

[19] Dubé MP, Stein JH, Aberg JA, et al. Guidelines for the evaluationa and management of dyslipidemia in human immunodeficiency vírus (HIV) - Infected Adutls Receiving Antiretroviral Therapy: Recommendations of the HIV Medicine Association of the Infectious Disease of America and the Adult AIDS Clinical Trials Group. Clin Infect Dis 2003; 37: 613-27.

[20] Third Report of the National Cholesterol Education Program (NCEP). Expert panel on detection, evaluation and treatment of high blood cholesterol in adults (adult treatment panel III) final report. Circulation 2002; 106: 3143-21.

[21] Fichtenbaum CJ, Gerber JG, Rosenkranz SL, et al. AIDS Clinical Trials Group. Pharmacokinetic interactions between protease inhibitors and statins in HIV seronegative volunteers: ACTG Study A5047. AIDS 2002; 16(4): 569-77.

[22] Calza L, Manfredi R, Chiodo F. Statins and fibrates for the treatment of hyperlipidaemia in HIV-infected patients receiving HAART. AIDS 2003; 17(6): 851-9.

[23] Bottorff MB. Statin safety and drug interactions: clinical implications. Am J Cardiol 2006; 97(8A): 27C-31C.

[24] Williams B, Feely J. Pharmacokinetic-pharmacodynamic drug in interactions with HMG-CoA reductase inhibitors. Clin Pharmacokinet 2002; 41: 434-70.

[25] Martin PD, Warwick MJ, Dane AL, et al. Metabolism, excretion, and pharmacokinetics of rosuvastatin in healthy adult male volunteers. Clin Ther 2003; 25(11): 2822-35.

[26] Cheng JW. Rosuvastatin in the management of hyperlipidemia. Clin Ther 2004; 26(9): 1368-87.
[27] Bottaro EG, Caravello O, Scapellato PG, et al. Rosuvastatin for the treatment of dyslipidemia in HIV-infected patients receiving highly active antiretroviral therapy. Enferm Infecc Microbiol Clin 2008; 26(6): 325-29.

[28] Calza L, Manfredi R, Colangeli V, Pocaterra D, Pavoni M, Chiodo F. Rosuvastatin, pravastatin, and atorvastatin for the treatment of hypercholesterolaemia in HIV-infected patients receiving protease inhibitors. Curr HIV Res 2008; 6(6): 572-8.

[29] Van der Lee M, Sankatsing R, Schippers E, et al. Pharmacokinetics and pharmacodynamics of combined use of lopinavir/ritonavir and rosuvastatin in HIV-infected patients. Antivir Ther 2007; 12(7): 1127-32.

[30] Merck/Schering-Plough Pharmaceuticals. Zetia (ezetimibe) product information. North Wales, PA, 2005.

[31] Negredo E, Molto J, Puig J, et al. Ezetimibe, a promising lipidlowering agent for the treatment of dyslipidaemia in HIV-infected patients with poor response to statins. AIDS 2006; 20(17): 215964.

[32] Gagné C, Bays HE, Weiss SR, et al. Ezetimibe Study Group. Efficacy and safety of ezetimibe added to ongoing statin therapy for treatment of patients with primary hypercholesterolemia. Am J Cardiol 2002; 90 (10):1084-91.

[33] Pearson TA, Denke MA, McBride PE, Battisti WP, Brady WE, Palmisano J. A community-based, randomized trial of ezetimibe added to statin therapy to attain NCEP ATP III goals for LDL cholesterol in hypercholesterolemic patients: the ezetimibe add-on to statin for effectiveness (EASE) trial. Mayo Clin Proc 2005; 80(5): 587-95.

[34] Kosoglou T, Statkevich P, Johnson-Levonas AO, Paolini JF, Bergman AJ, Alton KB. Ezetimibe: a review of its metabolism, pharmacokinetics and drug interactions. Clin Pharmacokinet 2005; 44 (5): 467-94.

[35] Stein E, Stender S, Mata P, et al. Ezetimibe Study Group. Achieving lipoprotein goals in patients at high risk with severe hypercholesterolemia: efficacy and safety of ezetimibe coadministered with atorvastatin. Am Heart J 2004; 148(3): 447-55.

[36] Farnier M, Freeman MW, Macdonell G, et al. The Ezetimibe Study Group. Efficacy and safety of the coadministration of ezetimibe with fenofibrate in patients with mixed hyperlipidaemia. Eur Heart J 2005; 26(9): 897-905.

[37] Coll B, Aragonés G, Parra S, Alonso-Villaverde C, Masana L. Ezetimibe effectively decreases LDL-cholesterol in HIV-infected patients. AIDS 2006; 20(12): 1675-7.

[38] Bennett MT, Johns KW, Bondy GP. Ezetimibe is effective when added to maximally tolerated lipid lowering therapy in patients with HIV. Lipids Health Dis 2007; 6: 15.

[39] Stebbing J, Asghar AK, Holmes P, Bower M, Isenman HL, Nelson M. Use of ezetimibe during HIV infection. J Antimicrob Chemother 2009; 63(1): 218-20.

[40] Berg-Wolf MV, Klibanov OM, Gaughan JP, Tedaldi EM. Ezetimibe combined with low-dose statin effectively lowers LDL in protease inhibitor treated patients. AIDS Patient Care STDS 2008; 22(6): 483-8.

[41] Simons LA, Hickie JB, Balasubramaniam S. On the effects of dietary n-3 fatty acids (Maxepa) on plasma lipids and lipoproteins in patients with hyperlipidaemia. Atherosclerosis 1985; 54(1): 7588 .

[42] Bang HO, Dyerberg J, Hjøorne N. The composition of food consumed by Greenland Eskimos. Acta Med Scand 1976; 200(1-2): 69-73.

[43] Weber P, Raederstorff D. Triglyceride-lowering effect of omega-3 LC-polyunsaturated fatty acids - a review. Nutr Metab Cardiovasc Dis $2000 ; 10(1): 28-37$.

[44] O'Keefe JH Jr, Harris WS. From Inuit to implementation: omega-3 fatty acids come of age. Mayo Clin Proc 2000; 75(6): 607-14.

[45] Harris WS, Connor WE, McMurry MP. The comparative reductions of the plasma lipids and lipoproteins by dietary polyunsaturated fats: salmon oil versus vegetable oils. Metabolism 1983; 32(2): 179-84.

[46] Stone NJ. Fish consumption, fish oil, lipids, and coronary heart disease. Circulation 1996; 94(9): 2337-40.

[47] Perez CF, Perales J, Fraile G. The hypolipemic effect of concentrated salmon oil rich in n-3 fatty acids. An Med Interna 1990; 7: 299-303.

[48] Kris-Etherton PM, Harris WS, Appel LJ. American Heart Association. Nutrition Committee. Fish consumption, fish oil, 
omega-3 fatty acids, and cardiovascular disease. Circulation 2002; 106 (21): 2747-57.

[49] Manfredi R, Calza L, Chiodo F. Polyunsaturated ethyl esters of n-3 fatty acids in HIV-infected patients with moderate hypertriglyceridemia: comparison with dietary and lifestyle changes, and fibrate therapy. J Acquir Immune Defic Syndr 2004; 36 (3): 878-80.

[50] Wohl DA, Tien HC, Busby M, et al. Randomized study of the safety and efficacy of fish oil (omega-3 fatty acid) supplementation with dietary and exercise counseling for the treatment of antiretroviral therapy-associated hypertriglyceridemia. Clin Infect Dis 2005; 41(10): 1498-504.

[51] Carter VM, Woolley I, Jolley D, Nyulasi I, Mijch A, Dart A. A randomised controlled trial of omega-3 fatty acid supplementation for the treatment of hypertriglyceridemia in HIV-infected males on highly active antiretroviral therapy. Sex Health 2006; 3: 287-90.
[52] De Truchis $\mathrm{P}$, Kirstetter $\mathrm{M}$, Perier A, et al. Reduction in triglyceride level with N-3 polyunsaturated fatty acids in HIVinfected patients taking potent antiretroviral therapy: a randomized prospective study. J Acquir Immune Defic Syndr 2007; 44(3): 27885 .

[53] Calza L, Manfredi R, Pocaterra D, Chiodo F. Risk of premature atherosclerosis and ischemic heart disease associated with HIV infection and antiretroviral therapy. J Infect 2008; 57(1): 16-32.

[54] Soler A, Deig E, Guil J, Rodríguez-Martín M, Guelar A, Pedrol E. Effectiveness and tolerance of atorvastatin for antiretroviral therapy-secondary dyslipemia. Med Clin (Barc) 2006; 127(7): 2502.

[55] Bader MS, Kelly DV. Diagnosis and management of common chronic metabolic complications in HIV-infected patients. Postgrad Med 2008; 120(4): 1-11.

(C) da Silva and Bárbaro; Licensee Bentham Open.

This is an open access article licensed under the terms of the Creative Commons Attribution Non-Commercial License (http://creativecommons.org/licenses/by$\mathrm{nc} / 3.0 /$ ) which permits unrestricted, non-commercial use, distribution and reproduction in any medium, provided the work is properly cited. 